\title{
The SNS-mediated Communication Modes and Teacher-student Relationships in Internet Era: Undergraduates' Perceptions from Four Chinese Universities
}

\author{
Hongling $\mathrm{GUO}^{1, *}$ \\ ${ }^{1}$ Public Administration and Law School, Southwest Jiaotong University, Chengdu, China, 610031 \\ ${ }^{*}$ Corresponding author. Email: hlg@swjtu.edu.cn
}

\begin{abstract}
The purpose of this paper is to understand undergraduates' views on based-SNS (Social Networking Sites) communication modes and teacher-student relationships in Chinese universities in the internet era. We investigated 420 undergraduates from four universities in Western China by semi-structured interview and questionnaire. Results indicate Social Networking Sites (WeChat and QQ) are the most popular communication platform of undergraduates in Chinese universities. All the participating undergraduates $(\mathrm{n}=420)$ have active SNS (QQ and WeChat) accounts and joined in class-group (QQ and WeChat group). 91\% of them thought QQ or WeChat could be used for learning. But the convenient communication modes did not play a great role in improving the teacher-student relationships. Only $29.5 \%$ of the participating undergraduates thought SNS can promote the relationship between teachers and students, and only $6.67 \%$ of them have chatted with the teachers on Social Networking Sites in private. $31.4 \%$ of them were satisfied with the current teacher-student relationships in the Universities and $71.5 \%$ thought the current teacher-student relationship needs to be improved. The undergraduates expect to build a harmonious, cooperative, mutual understanding and tolerant relationship between teachers and students. They understood the current situation and problems of the relationship between teachers and students, but they don't adopt proactive approach to improve it. We think building a good relationship between teachers and students is the common wish of teachers and students. It needs teachers and students to make joint efforts.
\end{abstract}

Keywords: Teacher-student Relationships; Communication modes; undergraduates; Social networking site

\section{INTRODUCTION}

The United Nations Educational, Scientific and Cultural Organization thinks that teacher-student relationship is the core of the education process. [1] Research has shown that the teacher-student relationships are good to improve students' study motivation, academic achievement, emotional and social development, engagement, investment of students in their studies and growth[2][3]. And good student-teacher relationships also can increase teachers' job satisfaction, ease their stress at work, reduce teachers burnout, enhance, work passion and augment their work hours and career commitments[4][5]

Good communication is vital to improve teacher-student relationships. [6] In internet era, communication between students and teachers is taking place via social networking sites (SNS) such as WeChat and QQ in Chinese colleges. The SNS have been widely adopted and have changed the way teachers communicate with students. SNS-based communication effectively extended the scope and setting in which teachers and students communicate. Do SNS increase the frequency of communication between teachers and students and improve the quality of teacher-student relationship in Chinese colleges? This issue has not attracted widespread attention although the pedagogical benefits of SNS have been extensively discussed[7]. Some scholars thought that teachers' role at large is changing in the internet era. [8] This change may affect, in turn, mutual perceptions and beliefs[9], thereby changing student-teacher relationships in colleges.

Some researchers examined on the associations between student-teacher relationship and student-teacher Facebook-mediated communication in the middle schools[9], and on the status and influence of the supervisor-students relationship in universities[10]. But few papers investigate Undergraduates' perceptions of the student-teacher relationships and communication mode in Chinese colleges in internet era.

This paper examined 420 undergraduates' perceptions on teacher-student relationship and teacher-student SNS-mediated communication from 4 Chinese colleges. This study focused on the following research questions:

(1) What are the characteristics of teacher-students communication via SNS in Chinese colleges? 
(2) What are undergraduates' attitudes towards SNS-mediated communication with teachers and the use of NSN for learning?

(3) What are the differences in undergraduates' perceptions of student-teacher relationships, based on the following variables? a) Types of NSN-mediated communication; b) Attitudes towards the use of NSN for learning.

\section{METHODOLOGY}

Methodology was qualitative and quantitative in nature, and was based on interviews and questionnaires for data collection. Due to the limitation of space, this article mainly presents the investigation and results of the qualitative part. The target population was undergraduates in universities.

\subsection{Procedure and Instruments}

Firstly, we conducted face-to-face semi-structured interviews with 50 undergraduates. They were asked to express their views on three aspects: (1) communication, including in the main ways of communication between them and teachers; main contents of communication; frequency of communication outside the classroom, whether to add friends with teachers. (2) attitudes, including in towards SNS-mediated communication with teachers and the use of SNS for learning; (3) evaluation and expectation, including in the evaluation of the current situation of teacher-student relationships in universities; expected ideal teacher-student relationship; the effect of social media on teacher-student relationships in universities.

Secondly, we constructed an exploratory questionnaire according to the interview results. The questionnaire consists of qualitative and quantitative parts. The qualitative questionnaire covers 15 questions in the above three aspects. Thirdly, data collection process. Data was collected during March-May 2019. With the help of the teacher, 4 undergraduates and 4 postgraduates from southwest Jiaotong university used their spare time to participate in the distribution and recovery of the questionnaire to four universities in Sichuan.

\subsection{Population}

Altogether, 420 undergraduates participated in this study. They were between $17-23$ years of age $(\mathrm{M}=20, \mathrm{SD}=1.8)$. There were 189 females (45\%) and 231 males (55\%). Participants were from four grades in four universities (Southwest Jiaotong University; Sichuan University; University of Electronic Science and Technology of China; Southwest University of Finance and Economics) in Sichuan in order to maximize reach out for varied participants.

\section{FINDINGS}

\subsection{Communication}

The survey results show $100 \%(n=420)$ the participating undergraduates have active SNS (QQ and WeChat) accounts and joined in class-group (QQ and WeChat group). $82.9 \%$ (348 of $42 \mathrm{o}$ ) undergraduates joined at least one of course group.

The modes of undergraduates' connection to their teachers are mainly the roll call and answering questions in class. $64.2 \%$ (270 of 420$)$ of the undergraduates reported no communication with teachers in class. Group-based communication was the most popular outside class such as posting course information and notices. $75.3 \%$ (316 of 420 ) of the undergraduates reported no interaction with teachers in group outside of class.

Only $7.61 \%$ (32 of 420 ) the participating undergraduates have at least one of their teachers as a WeChat-friend or QQ-friend exclude class or course group. Among the Connected group (32 of 420), the main contents the participating undergraduates communicated to their teachers outside class (This question can be multiple-choice) were different. $75 \%$ (24 of 32) the participating undergraduates private chatted with the teacher about learning (dissertation; scientific research topics; assignment), 25\% (8 of 32) asking for leave; $9.4 \%$ (3 of 32) sharing about their personal life with teachers; $9.4 \%$ ( 3 of 32 ) talking about else things. $53.1 \%$ (17 of 32 ) undergraduates browsed and gave the thumbs-up on teachers' post updates at least 1 time. $25 \%$ (8 of 32) undergraduates browse occasionally but no commenting on. From frequency of communication outside the classroom, $18.75 \%$ (6 of 32$)$ the participating undergraduate s communicated with teachers more than 5 times; $21.8 \%$ (7 of 32 ) the participating undergraduates had only 1 time; $12.5 \%$ (4 of 32 ) undergraduates had no interaction.

When asked if you would like to have one of your teachers to be good friend in QQ or WeChat, only $19.8 \%$ (83 of 420) undergraduates have no but would like to have one of their teachers to be good friend in QQ or WeChat. $66.9 \% \quad(281$ of 420$)$ the participating undergraduates have no and do not wish to have any of their current teacher as a SNS-friend. 5.71\% (24 of 420) undergraduates don't care.

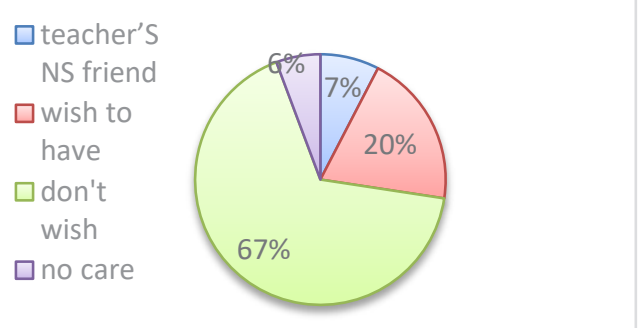

Figure 1. The undergraduates' willingness of communication to their teachers outside of class 


\subsection{Attitudes}

This part mainly investigated the attitudes of Undergraduates in two aspects.

At first, the participating undergraduates were asked whether they thought QQ or WeChat could be used for learning. Overall, 91\% responded with a "Yes"; (see Fig. 2). Analysing, these attitudes by type of QQ or WeChat -friendship with teachers (connected, wannabe connected, not wannabe connected) reveal differences between the groups. In the Connected group, $96.8 \%$ (31 of 32) the undergraduates agreed QQ or WeChat can be used for learning, while $95.2 \%$ (79 of 83) of the Wannabe Connected group agreed QQ or WeChat can be used for learning. Regarding the Not Wannabe Connected group, 90.4\% (254 of 281), and Not care group 91. 6\% (22 of 24) thought that QQ or WeChat can be used for learning.

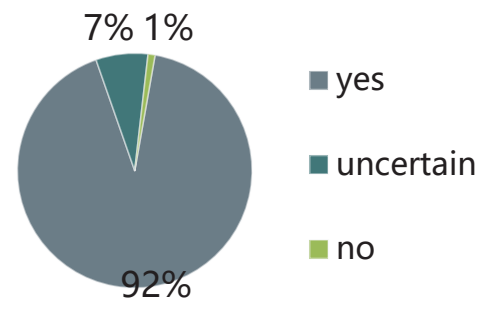

Figure 2. QQ or WeChat could be used for learning

At second, we asked the participating undergraduates "if you have to communicate with teachers, which way would you prefer? (i. e. QQ or WeChat, phone, E-mail, face to face;)". $68 \%$ (286 of 420) chose "QQ or WeChat"(see Fig3).

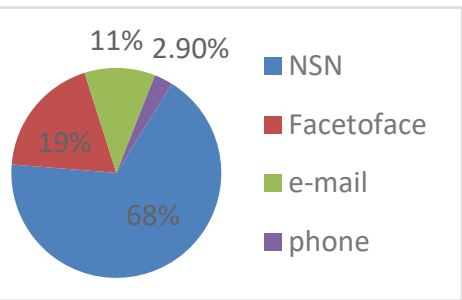

Figure 3. Favourite tool for communicating with teachers

\subsection{Evaluation and Expectation}

This part mainly investigated undergraduates' evaluation and expectation of teacher-student relationships.

Firstly, we asked the participating undergraduates whether they were satisfied with the current teacher-student relationships. Only30.4\%\% responded with a "Very satisfied" and "satisfied"(see Fig. 4)

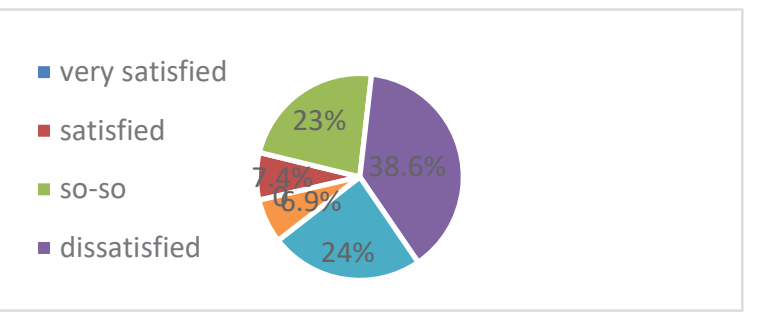

Figure 4. Feelings on the current teacher-student relationship

When the participating undergraduates were asked "What do you think are the obstacles affecting the relationship between teachers and students (This question can be multiple-choice)", the top three are (1)81\% thought "lack of communication between teachers and students"; (2) $62 \%$ thought "the universal instrumental rationality in the teacher-student relationship"; (3) 49\% thought "under the impact of new media and online classes, teachers' authority is reduced". While our questionnaire survey also showed $44.3 \%$ responded "go to class for credits"; $84.7 \%$ don't turn to teachers when they have problems. Secondly, we investigated undergraduates' expectation to teacher-student relationships. When the participating undergraduates were asked whether they think the teacher-student relationship needs to be improved, $25 \%$ of participating undergraduates responded with a "highly necessary"; 46. 5\% "necessary" (see Fig5).

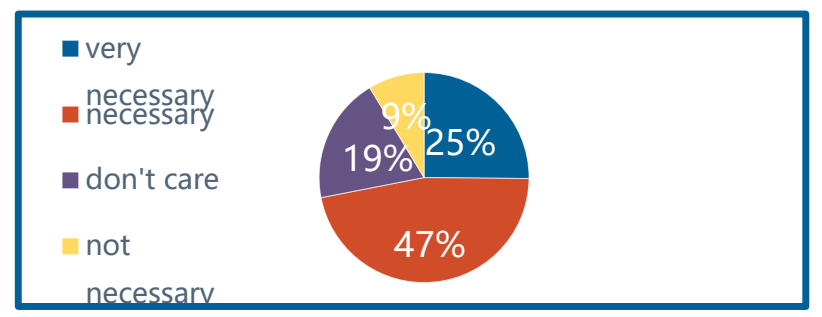

Figure 5. The necessity of improving the relationship between teachers and students

And our questionnaire survey also shows the ideal relationships between teachers and students, in the eyes of undergraduates, were harmonious(306 of 420), mutual aid and cooperation(286 of 420), mutual understanding (235 of 420) and tolerance (167 of 420).

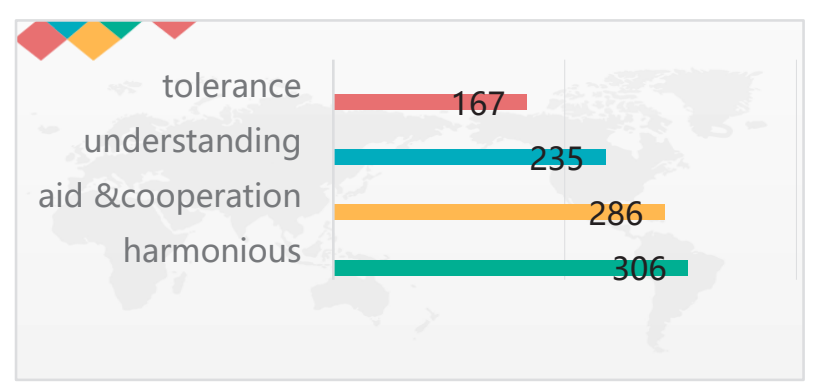

Figure 6. Ideal teacher-student relationship expected by undergraduates 
They believe that teachers should play the following role in the relationships between teachers and students: knowledge imparters (77.6\%), role models (56.9\%), life mentors (49\%), intimate friends (39\%), supporters of learning (36.4\%). (see Fig. 7) When we asked the participating undergraduates "do you think social networks can promote the relationship between teachers and students", only $29.5 \%$ of them chose "yes".

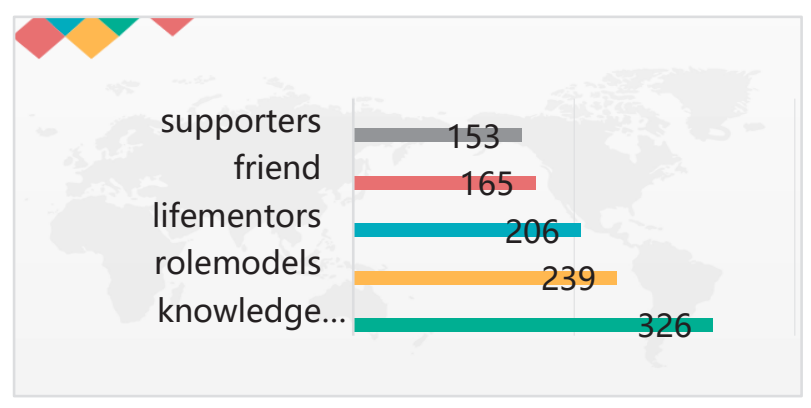

Figure 7. The role of teachers expected by undergraduates

\section{CONCLUSIONS AND DISCUSSION}

With the rapid development of the Internet, the status and function of teachers have changed in teaching activities, which led to indifferent and lack of trust relationships between teachers and students. The obstructions of the trust relationships between teachers and students in universities are "lack of communication" and "bidirectional segregation between physical place and the psychological place for teachers and students." [11] While SNS can promote social, interpersonal connections and communication through effectively breaks through the isolation of time and space. Such the modes of connections and communication might also have important implications in the educational context. In this study, we explored undergraduates' perceptions on SNS-mediated communication modes and student-teacher relationships. According to our Research, we can draw the following conclusions:

(1) Though Social Networking Sites (WeChat and QQ) are the most popular communication platform of undergraduates in Chinese universities, however, teachers and students rarely use it for communication in private. The survey results show all of the participating undergraduates joined in the class-group, but only $6.67 \%$ the participating undergraduates have chatted with the teacher in private.

(2) The lack of communication between teachers and students is not caused by physical isolation, but more by undergraduates who believe that there is no need for communication. We found $66.9 \%$ the participating undergraduates do not wish to have any of their current teacher as a SNS-friend. This conclusion provides evidence for the following views: "The teacher-student relationships becomes a simple way of "teaching" and "learning" formed according to the division of roles Professional relationship"[12].
(3) The undergraduates have a positive attitude towards using NSN for learning. Overall, $91 \%$ of the participating undergraduates thought QQ or WeChat can be used for learning, $82.9 \%$ of them joined at least one of course groups.

(4) The convenient communication modes did not play a great role in improving the teacher-student relationships. The survey shows only $29.5 \%$ of the participating undergraduates thought social networks can promote the relationship between teachers and students. Though $68 \%$ of them prefer to communicate with teachers on SNS, but $66.9 \%$ do not wish to have any of their current teacher as a SNS-friend. This is a very contradictory state, which needs further study.

(5) The undergraduates understood the current situation and problems of the relationship between teachers and students, but they don't adopt proactive approach to improve it. Our questionnaire survey shows $69.6 \%$ of the participating undergraduates were dissatisfied with the current teacher-student relationships. Therefore $71.5 \%$ of them thought the current teacher-student relationship needs to be improved. But only $6.7 \%$ of the participating undergraduates communicated with teachers more than 1 times outside of class. $84.7 \%$ of them don't turn to teachers when they have any problems.

(6) Building a good teacher-student relationship is the common wish of teachers and students. Some research thought democracy and equality, respect and trust, mutual assistance and cooperation, independence and innovation are the characteristics of the new university teacher-student relationships. [8][12][13]. This view is consistent with our findings.

Based on our research results, we suggest that future Research on this topic can include broader and more diverse samples from different countries and regions, as well as different types of social networking sites. And it is necessary to understand undergraduates' views on this topic. More importantly, we need to focus on how to make full use of social networks to strengthen the communication between teachers and students in order to improve the relationship between teachers and students. Of course, this study is not without limitations. Firstly, the research samples are non-random samples from four universities in Chengdu. Maybe the situation of universities in other regions is different. Secondly this study was conducted in China, maybe in other some countries, under different cultural circumstances and educational policies the results may be biased. In addition, our data was collected during March - May 2019. COVID-19 have an enormous impact on the world, which is changing Classroom teaching modes and communication ways between teachers and students in Universities. Maybe after COVID-19, data was collected can be different. 


\section{REFERENCES}

[1] Donghui, Hao From Displine to Communication: Reflections on the Reconstruction of teacher-student relationships, Knowledge Cultures; Woodside Vol. 7, Iss. 1, (2019): 44-48.

[2] Alsttair Henry, Teacher Student Relationships and L2 Motivation, [J] The Modern Language Journal, 2018, 102(1), 218-241.

[3] David Dennie, The impact of teacher student relationships and classroom engagement on student growth percentiles of 7 th and 8 th grade students [J]Psychology in the Schools, 201956(5), 765-780.

[4] Tzu Ling Lai, Effects of Student Teacher Congruence on Students Learning Performance: A Dyadic

Approach[J]Social Science Quarterly, 2015, 96(5), 1424-1435.

[5] Shiri Lavy, Shira Bocke, A Path to Teacher Happiness? A Sense of Meaning Affects Teacher-Student Relationships, Which Affect Job Satisfaction J Happiness Study (2018) 19:1485-1503.

[6] Donghui, Hao From Displine to Communication: Reflections on the Reconstruction of teacher-student relationships, Knowledge Cultures; Woodside Vol. 7, Iss. 1, (2019): 44-48.

[7] Manca, S., \& Ranieri, M. (2017). Implications of Social Network Sites for Teaching and Learning: Where We Are and Where We Want to Go. Education and Information Technologies, 22(2), 605-622.
[8] Hongling GUO. (2019) Reconstruction of the Teacher-student Relationship in Chinese Universities in Internet-era. 2019 9th international conference on social science and education research, Kitakyushu, Japa. 2019. 10. 145-149.

[9] Alona Forkosh-Baruch \& Arnon Hershkovitz. Broadening communication yet holding back: Teachers' perceptions of their relationship with students in the SNS-era. Educational information technology (2018) 23:725-740.

[10] Yu Xiaomin, Zhao Jinru, Wu Xin. Empirical Analysis on the Status and Influence of the Supervisor-Students Relationship in Universities. J Tianjin university, (2017)19(2), 157-162. (In Chinese)

[11] XIANG Dong-chun. The Research about the obstruction and countermeasure of the trust relationship between university faculty and students. Teacher Education Research, (2016) 28(2), 15-19. (In Chinese)

[12] ZHAO Zhen-jie Exploring the Relationship Management to Between University Faculty and Student in Current China. Teacher Education Research ;(2015), 27(5) 89-94.

[13] WANG Deng deng, YUAN Liqin, The Review of Ten Years' Domestic Research on the Relationship Between College Teachers and Students, Heilongjiang Research on Higher Education, (2016), 262(2)97-101. (In Chinese) 